\title{
Theoretical study of the structural dependence of nuclear quadrupole frequencies in high- $T_{c}$ superconductors
}

\author{
M. E. Garcia and K. H. Bennemann \\ Institute for Theoretical Physics, Freie Universität Berlin, Arnimallee 14, D-1000 Berlin 33, Federal Republic of Germany \\ (Received 18 January 1989; revised manuscript received 26 May 1989)
}

\begin{abstract}
The remarkable difference between the nuclear quadrupole frequencies $v_{Q}$ of $\mathrm{Cu}(1)$ and $\mathrm{Cu}(2)$ in $\mathrm{YBa}_{2} \mathrm{Cu}_{3} \mathrm{O}_{6}$ and $\mathrm{YBa}_{2} \mathrm{Cu}_{3} \mathrm{O}_{7}$ is analyzed. We calculate the ionic contribution to the electric field gradients and estimate, by using experimental results for $\mathrm{Cu}_{2} \mathrm{O}$ and $\mathrm{La}_{2} \mathrm{CuO}_{4}$, the contribution of the $d$ valence electrons. Thus, we determine $v_{Q 1}, v_{Q 2}$, and the asymmetry parameter $\eta$ for $\mathrm{YBa}_{4} \mathrm{Cu}_{3} \mathrm{O}_{6}$ and $\mathrm{YBa}_{2} \mathrm{Cu}_{3} \mathrm{O}_{7}$. The number of holes in the $\mathrm{Cu}-\mathrm{O}$ planes and chains is found to be importint for the different behavior of $v_{Q 1}$ and $v_{Q 2}$.
\end{abstract}

Nuclear quadrupole resonance (NQR) can give important information about the electronic structure of solids, since the nuclear quadrupole coupling constant is proportional to the total electric field gradient $\left(q_{i j}\right)$ at the nucleus. An interpretation of the experimental data within a simple electronic physical picture is possible. However, in general and especially for complex systems, a quantitative analysis is difficult. Many NQR experiments have been performed for: the various high- $T_{c}$ compounds, and particularly for both copper sites $\mathrm{Cu}(1)$ and $\mathrm{Cu}(2)$ in $\mathrm{YBa}_{2} \mathrm{Cu}_{3} \mathrm{O}_{7-8^{\circ}}{ }^{1-6}$ Obviously, different charge configurations expected in such systems may be reflected in NQR results. However, due to the complicated structure of high- $T_{c}$ materials, it remains difficult to obtain from the values of the NQR frequencies $\nu_{O}$ (and consequently of the total field gradient $q_{i j}$ ) for $\mathrm{Cu}(1)$ and $\mathrm{Cu}(2)$ a complete understanding of the ionic charge distribution. Furthermore, it is by no means clear whether such high$T_{c}$ materials can be treated as dominantly ionic in character and that the sovalent character of the $\mathrm{Cu}-\mathrm{O}$ bonds may be neglected.

Experimental re'sults for antiferromagnetic $\mathrm{YBa}_{2} \mathrm{Cu}_{3} \mathrm{O}_{6}$ show ${ }^{7}$ an inversion of the magnitudes of $v_{Q_{1}}$ and $v_{Q_{2}}$, which refer to $\mathrm{Cu}(1)$ and $\mathrm{Cu}(2)$, respectively, with respect to these values in $\mathrm{YBa}_{2} \mathrm{Cu}_{3} \mathrm{O}_{7}$. One observes $v_{Q 1}=30.11$ $\mathrm{MHz}$ and $v_{Q 2}=22.87 \mathrm{MHz}$ in $\mathrm{YBa}_{2} \mathrm{Cu}_{3} \mathrm{O}_{6}{ }^{7}$ and $v_{Q 1}=22$ $\mathrm{MHz}$ and $v_{Q 2}=31.5 \mathrm{MHz}$ in $\mathrm{YBa}_{2} \mathrm{Cu}_{3} \mathrm{O}_{7 .}{ }^{4-6}$ This interesting difference could suggest that $v_{Q}$ is a sensitive quantity reflecting changes in the electronic properties of both compounds iwhose crystal structures are similar). The purpose of our analysis is to estimate the quadrupole frequencies in $\mathrm{YB} \varepsilon_{2} \mathrm{Cu}_{3} \mathrm{O}_{6}$ and $\mathrm{YBa}_{2} \mathrm{Cu}_{3} \mathrm{O}_{7}$ and to explain the experimental results. We use simple assumptions about the electronic structure and consider explicity the existence of covalent $\mathrm{Cu}-\mathrm{O}$ bonds. Furthermore, for determining the valence electron contribution to the electric field gradient $q_{i j}$ we use experimental results for $\mathrm{Cu}_{2} \mathrm{O}$ and $\mathrm{La}_{2} \mathrm{CuO}_{4}$.

The quadrupole frequency for the ${ }^{63} \mathrm{Cu}$ nucleus (with nuclear spin $I=\frac{3}{2}$ ) is given by

$$
v_{Q}=\frac{1}{2} e^{2} Q q_{z z}^{\text {tot }}\left(1+\eta^{2} / 3\right)^{1 / 2},
$$

where $Q$ is the nuclear quadrupole moment, $q_{z z}^{\text {tot }}$ the largest component ( $z$ component) of the total field gradient tensor in a set of principal axes, and $\eta=\left(q_{x x}-q_{y y}\right) / q_{z z}$ refers to the asymmetry pararneter. From a general expression of $q_{z z}^{\text {tot }}$ as a function of the coordinates of all the nuclei and electrons in the solid ${ }^{8}$ one can derive an approximate expression, ${ }^{9}$ in which the sources of the electric field gradient at a certain nucleus are the outer (or valence) electrons with aspherical wave functions and the other ions (considered in lowest approximation as an infinite arrangement of point charges). Then, if the principal axes of both ionic and valence contributions are the same, Eq. (1) may be rewritten as

$$
v_{Q}=\left[\frac{1}{2} e^{2} Q\left(1-\gamma_{\infty}\right) q_{z z}^{\text {ionic }}+q_{\mathrm{val}}\right]\left(1+\eta^{2} / 3\right)^{1 / 2},
$$

where $\gamma_{\infty}$ refers to the Sternheimer antishielding factor, ${ }^{10}$ which accounts for the contribution from the distortion of the $\mathrm{Cu}$ ion both by the local field gradient and by the quadrupolar field of the nucleus. The contribution to the field gradients due to the ionic lattice is given by the term

$$
\frac{1}{2} e^{2} Q\left(1-\gamma_{\infty}\right) q_{\mathrm{zz}}^{\text {ionic }},
$$

and the term

$$
q_{\mathrm{val}}=\frac{1}{2}(1-R) e^{2} Q q_{\mathrm{zz}}^{\mathrm{val}}
$$

refers to the field gradients produced by the valence electrons at the $\mathrm{Cu}$ sites, in which the shielding factor $R$ describes the shielding by core electrons. ${ }^{10}$ The asymmetry parameter $\eta$ is written as

$$
\eta=\left(q_{x x}^{T}-q_{y y}^{T}\right) / q_{z z}^{T}
$$

where

$$
q_{i i}^{T}=q_{i i}^{\text {ionic }}+q_{i i}^{\mathrm{val}} .
$$

$q_{z z}^{\text {val }}$ results from the electrons (holes) in the open $d \mathrm{Cu}$ shells. In terms of the number of holes in the different $d$ orbitals, $q_{z z}^{\text {val }}$ may be written as 


$$
\begin{aligned}
q_{z z}^{\mathrm{val}=} & A\left\langle r^{-3}\right\rangle_{3 d}\left[n_{h}\left(3 d_{3 z^{2}-r^{2}}\right)-n_{h}\left(3 d_{x^{2}-y^{2}}\right)\right. \\
& -n_{h}\left(3 d_{x y}\right)+\frac{1}{2} n_{h}\left(3 d_{x z}\right) \\
& \left.-\frac{1}{2} n_{h}\left(3 d_{y z}\right)\right]
\end{aligned}
$$

where $A$ is a constant. In what follows we will assume that the orbitals $3 d_{x y}, 3 d_{x z}$, and $3 d_{y z}$ are below the Fermi level and that consequently their contributions vanish.

Note that previously Adrian ${ }^{11}$ has calculated $v_{Q 1}$ and $v_{Q 2}$ in $\mathrm{YBa}_{2} \mathrm{Cu}_{3} \mathrm{O}_{7}$ using Eq. (2). Although his results seem to be in agreement with experiment, one should note that he makes two crude assumptions. First, he considers $\gamma_{\infty}$ to be independent of the ionic charge and he takes $\gamma_{\infty}^{\mathrm{Cu}^{2+}}=-17$, which is the calculated value ${ }^{12}$ for $\mathrm{Cu}^{+}$. A calculation of $\gamma_{\infty}$ for $\mathrm{Cu}^{2+}$ has been carried out by Gupta et al. ${ }^{13}$ and gives $\gamma_{\infty}^{\mathrm{Cu}^{2+}}=-7.59$. Using this value, Adrian results are no longer close to the experimental values. ${ }^{14}$ Furthermore, performing his calculations in $\mathrm{YBa}_{2} \mathrm{Cu}_{3} \mathrm{O}_{6}$ one obtains values which are far away (even qualitatively) from the experimental results. Second, he assumes that only $\mathrm{Cu}^{2+}$ contributes to $q_{\mathrm{val}}$.

In the following we determine $v_{Q_{1}}$ and $v_{Q_{2}}$ and the asymmetry parameter $\eta$ for $\mathrm{YBa}_{2} \mathrm{Cu}_{3} \mathrm{O}_{6}$ and $\mathrm{YBa}_{2} \mathrm{Cu}_{3} \mathrm{O}_{7}$ from Eq. (2) by calculating directly $\frac{1}{2} e^{2} Q q_{z z}^{\text {ionic }}$ and by estimating $q_{\text {val }}$ using experimental results for $\mathrm{Cu}_{2} \mathrm{O}$ and $\mathrm{La}_{2} \mathrm{CuO}_{4}$.

We have calculated the ionic contribution $\frac{1}{2} e^{2} Q q_{\mathrm{zz}}^{\text {ionic }}$ for $\mathrm{Cu}(1)$ and $\mathrm{Cu}(2)$ in both $\mathrm{YBa}_{2} \mathrm{Cu}_{3} \mathrm{O}_{6}$ and $\mathrm{YBa}_{2} \mathrm{Cu}_{3} \mathrm{O}_{7}$ using the Evjen method ${ }^{15}$ (to insure the convergence of the numerical summations). The following charge configurations are assumed: $\mathrm{Y}^{3+}, \mathrm{Ba}^{2+}$ for both compounds, and $\mathrm{O}(2)^{2-}, \mathrm{O}(3)^{2-}, \mathrm{Cu}(1)^{+} \mathrm{Cu}(2)^{2+} \mathrm{O}(4)^{2-}$ for $\mathrm{YBa}_{2} \mathrm{Cu}_{3} \mathrm{O}_{6}$, whereas $\mathrm{O}(2)^{1.95-}, \mathrm{O}(3)^{1.95-}, \mathrm{Cu}(1)^{2.4+}$, $\mathrm{Cu}(2)^{2.1+}, \mathrm{O}(4)^{2-}, \mathrm{O}(1)^{1.8-}$ for $\mathrm{YBa}_{2} \mathrm{Cu}_{3} \mathrm{O}_{7} . \quad \mathrm{O}(1)$ refers to the oxygen atoms along the chains, and $\mathrm{O}(4)$ to the ox- ygen atoms above and below $\mathrm{Cu}(1)$. Note, in the assumed charge distribution for $\mathrm{YBa}_{2} \mathrm{Cu}_{3} \mathrm{O}_{7}$, each $\mathrm{CuO}_{2}$ plane and the chain have 0.2 and 0.6 holes, respectively, near to the values observed in recent experiments. ${ }^{16}$ It must be mentioned that $\frac{1}{2} e^{2} Q q_{z z}^{\text {ionic }}$ is not very sensitive to small charge changes. ${ }^{17}$ However, the holes will contribute to $q_{\mathrm{val}}$. The values for the $\frac{1}{2}\left(1-\gamma_{\infty}\right) e^{2} Q q_{z z}^{\text {ionic }}$ and the asymmetry parameter $\eta$ obtained for $\mathrm{Cu}(1)$ and $\mathrm{Cu}(2)$ in $\mathrm{YBa}_{2} \mathrm{Cu}_{3} \mathrm{O}_{6}$ and $\mathrm{YBa}_{2} \mathrm{Cu}_{3} \mathrm{O}_{7}$ are shown in Table $\mathrm{I}$. These results indicate that the ionic contribution alone cannot explain the behavior of $v_{Q}$ in $\mathrm{YBa}_{2} \mathrm{Cu}_{3} \mathrm{O}_{7}$.

Since a first-principles calculation of $q_{\text {val }}$ seems still a very complicated and not yet solved many-body problem and since we only attempt to explain qualitatively the behavior of $v_{Q 1}$ and $v_{Q 2}$, we will estimate $q_{\text {val }}$ for $\mathrm{Cu}$ using simple physical arguments and with the help of experimental data for $v_{Q}$ in the related compounds $\mathrm{Cu}_{2} \mathrm{O}$ and $\mathrm{La}_{2} \mathrm{CuO}_{4}$.

For example, $q_{\text {val }}$ for $\mathrm{Cu}(1)$ in $\mathrm{YBa}_{2} \mathrm{Cu}_{3} \mathrm{O}_{6}$ may be estimated from $v_{Q}$ in $\mathrm{Cu}_{2} \mathrm{O}$, where copper is also in the state $\mathrm{Cu}^{+}$. Since $\mathrm{Cu}_{2} \mathrm{O}$ is mainly ionic ${ }^{18,19}$ and an isolated $\mathrm{Cu}^{+}$is spherically symmetric, it seems reasonable to take $q_{\text {val }}=0 .^{20-22}$ Our calculation of the ionic contribution for $\mathrm{Cu}$ in $\mathrm{Cu}_{2} \mathrm{O}$ gives $\frac{1}{2} e^{2} Q q_{\mathrm{zz}}^{\text {ionic }}=4.01 \mathrm{Mhz}$, the $z$ principal axis being the $(1,1,1)$ axis. The experimental values in $\mathrm{Cu}_{2} \mathrm{O}$ are $v_{Q}=26 \mathrm{MHz}$, and $\eta=0 .{ }^{23}$ Note that, using an effective $\left(1-\gamma_{\infty}\right)=-6.48$, one could obtain, from our calculated value $4.01 \mathrm{MHz}$ for $\frac{1}{2} e^{2} Q q_{z z}^{\text {ionic }}$, the observed experimental value for $v_{Q}$. In order to determine now the $\mathrm{Cu}(1)$ quadrupole frequency in $\mathrm{YBa}_{2} \mathrm{Cu}_{3} \mathrm{O}_{6}$ we reason as follows. The coordination $\mathrm{O}(4)-\mathrm{Cu}(1)-\mathrm{O}(4)$ is very similar to that of $\mathrm{Cu}$ in $\mathrm{Cu}_{2} \mathrm{O}$. The only difference is given by the interatomic distances, namely the $\mathrm{Cu}-\mathrm{O}$ distance is $1.84 \AA$ for $\mathrm{Cu}_{2} \mathrm{O},{ }^{24}$ whereas the $\mathrm{Cu}(1)$ $\mathrm{O}(4)$ distance for $\mathrm{YBa}_{2} \mathrm{Cu}_{3} \mathrm{O}_{6}$ (Ref. 25) is $1.79 \AA$. Since this change in the interatomic distances is relatively small

TABLE I. Calculated results for the field gradient contribution $\frac{1}{2} e^{2} Q\left(1-\gamma_{\infty}\right) q_{z z}^{\text {ionic }}$ of the lattice and the asymmetry parameter $\eta$. The $\mathrm{Cu} d$-electron field gradient contribution $q_{\mathrm{val}}$ is estimated from experimental results for the NQR resonance frequency $v_{Q}$ in $\mathrm{Cu}_{2} \mathrm{O}$ and $\mathrm{La}_{2} \mathrm{CuO}_{4}$; modifications due to changes in covalency, see discussion in text, are included. Results for $q_{\text {val }}$ given in brackets follow if values derived for $\mathrm{La}_{2} \mathrm{CuO}_{4}$ are used.

\begin{tabular}{lcc}
\hline \hline & $\mathrm{YBa}_{2} \mathrm{Cu}_{3} \mathrm{O}_{6}$ & $\mathrm{YBa}_{2} \mathrm{Cu}_{3} \mathrm{O}_{7}$ \\
\hline$\frac{1}{2} e^{2} Q q_{2 z}^{\text {ionic }}(\mathrm{Cu}(1))$ & $4.86 \mathrm{MHz}$ & $-32.36 \mathrm{MHz}$ \\
$\frac{1}{2} e^{2} Q\left(1-\gamma_{\infty}\right) q_{z z}^{\text {ionic }}(\mathrm{Cu}(2))$ & $-22.5 \mathrm{MHz}$ & $-18.9 \mathrm{MHz}$ \\
$q_{\text {val }}(\mathrm{Cu}(1))$ & $0.0 \mathrm{MHz}$ & $52.1 \mathrm{MHz}$ \\
$q_{\text {val }}(\mathrm{Cu}(2))$ & $45.4 \mathrm{MHz}$ & $47.1 \mathrm{MHz}$ \\
& $(52.1 \mathrm{MHz})$ & \\
$\eta_{1}$ & 0.0 & 0.67 \\
$\eta_{1}^{\text {expt }}$ & 0.0 & $\sim 1.0$ \\
$\eta_{2}$ & 0.0 & 0.07 \\
$\eta_{2}^{\text {expt }}$ & 0.0 & $0.01-0.1$ \\
$v_{Q 1}$ & $31.5 \mathrm{MHz}$ & $21.2 \mathrm{MHz}$ \\
$v_{Q}^{\text {expt }}$ & $30.11 \mathrm{MHz}$ & $22.0 \mathrm{MHz}$ \\
$v_{Q 2}$ & $22.87(29.6) \mathrm{MHz}$ & $28.0 \mathrm{MHz}$ \\
$v_{Q 2}^{\text {expt }}$ & $22.87 \mathrm{MHz}$ & $31.5 \mathrm{MHz}$ \\
\hline \hline
\end{tabular}


and the distance to the planes is still large, ${ }^{25}$ we assume that the covalent contribution (due to the $\hat{q}_{\mathrm{val}}$ ) to $v_{Q 1}$ is small. Then, if the antishielding factor is the same in both compounds, then we can write

$$
v_{Q 1} \simeq v_{Q}\left(\mathrm{Cu}_{2} \mathrm{O}\right) q_{z z}^{\text {ionic }}\left(\mathrm{YBa}_{2} \mathrm{Cu}_{3} \mathrm{O}_{6}\right) / q_{z z}^{\text {ionic }}\left(\mathrm{Cu}_{2} \mathrm{O}\right) .
$$

Our calculated valıe for $\frac{1}{2} e^{2} Q q_{z z}^{\text {ionic }}$ in $\mathrm{YBa}_{2} \mathrm{Cu}_{3} \mathrm{O}_{6}$ is 4.86 $\mathrm{MHz}$ (where the $:$ principal axis is the $c$ axis). Then, $v_{Q 1}=31.5 \mathrm{MHz}$ (espt: $30.11 \mathrm{MHz}$ ). Note that this value might be smaller if' a small amount of holes is present in the $3 d_{3 z^{2}-r^{2}}$ orbital of $\mathrm{Cu}(1)$.

In order to estimate $q_{\text {val }}$ and $v_{Q}$ for the other $\mathrm{Cu}$ atoms in $\mathrm{YBa}_{2} \mathrm{Cu}_{3} \mathrm{O}_{6}$ and $\mathrm{YBa} \mathrm{C}_{2} \mathrm{Cu}_{3} \mathrm{O}_{7}$, we use experimental data for $\mathrm{Cu}^{2+}$. Recently, $\mathrm{NQR}$ measurements have been performed on the $\mathrm{La}_{2} \mathrm{CuO}_{4-\delta}$ compound, ${ }^{26}$ where $\mathrm{Cu}$ is approximately $\mathrm{Cu}^{2+}$. The quadrupole frequency for $\mathrm{Cu}$ was observed to be $v_{Q}==31.9 \mathrm{MHz}$. Our calculation yields

$$
\frac{1}{2} e^{2} Q q_{z z}^{\text {ionic }}=-2.35 \mathrm{MHz}
$$

for this compound. Then, using $\gamma_{\infty}^{\mathrm{Cu}^{2+}}=-7.59,{ }^{13}$ we derive from Eq. (2) $q_{\mathrm{val}}=52.1 \mathrm{MHz}$. Taking into account that the $z$ principal axis is the $c$ axis, and that the quadrupole moment is negative $\left[Q\left({ }^{63} \mathrm{Cu}\right)=-0.211 \mathrm{~b}\right.$ (Ref. 27)], it is possible to understand, from Eq. (3), the positive value of $q_{\mathrm{val}}$ as resulting from holes in the $3 d_{x^{2}-y^{2}}$ orbital of $\mathrm{Cu}$. If the number of holes were $n_{h}=1$, then $\mathrm{Cu}$ would be in a pure $\mathrm{Cu}^{2+}$ state and one would calculate according to Adrian ${ }^{11} q_{\mathrm{val}}=95.5 \mathrm{MHz}$. The smaller value $q_{\mathrm{val}}=52.1 \mathrm{MHz}$ derived by us indicates stronger covalent bonding. If we assurne that $\mathrm{Cu}(2)$ in $\mathrm{YBa}_{2} \mathrm{Cu}_{3} \mathrm{O}_{6}$ has nearly the same configuration as $\mathrm{Cu}$ in $\mathrm{La}_{2} \mathrm{CuO}_{4}$, and thus insert $q_{\mathrm{val}}=52.1 \mathrm{MHz}$ and our calculated value for $\mathrm{YBa}_{2} \mathrm{Cu}_{3} \mathrm{O}_{6}$ of

$$
\frac{1}{2} e^{2} Q q_{z z}^{\text {ionic }}=-2.62 \mathrm{MHz}
$$

in Eq. (2), we obtain

$$
v_{Q 2}\left(\mathrm{YBa}_{2} \mathrm{Cu}_{3} \mathrm{Cl}_{6}\right) \simeq 29.6 \mathrm{MHz} \text {. }
$$

This is somewhat larger than the experimental value $22.87 \mathrm{MHz}$. Howe;ver, there are structural differences between $\mathrm{La}_{2} \mathrm{CuO}_{4}$ and $\mathrm{YBa}_{2} \mathrm{Cu}_{3} \mathrm{O}_{6}$. The oxygen atoms above and below $\mathrm{Cu}(2)$ along the $c$ axis have different coordinations. In $\mathrm{La}_{2} \mathrm{CuO}_{4}$ this type of oxygen lies between $\mathrm{Cu}(2)$ and $\mathrm{L}$ a, whereas in $\mathrm{YBa}_{2} \mathrm{Cu}_{3} \mathrm{O}_{6}$ it is located between $\mathrm{Cu}(2)$ and $\mathrm{Cu}(1)$ [closer to $\mathrm{Cu}(1)$ than to $\mathrm{Cu}(2)$ ]. Furthermore, in the case of the La compound, the oxygen atoms are rather $\mathrm{C}^{2-}$, because they have only the possibility to make covalent bonding with $\mathrm{Cu}$, which is $2.4 \AA$ away. In the $\mathrm{YBa}_{2} \mathrm{Cu}_{3} \mathrm{O}_{6}$ the $\mathrm{O}(4)$ may form at least weak bonds with the $\mathrm{Cu}$ neighbors $[\mathrm{Cu}(1)$ and $\mathrm{Cu}(2)]$, through the hopping matrix elements between $p_{z}$ orbital of $\mathrm{O}(4)$ and the $3 d d_{3 z^{2}-r^{2}}$ orbitals of the $\mathrm{Cu}$ atoms. This would favor the existence of holes in these orbitals (which in the ionic picture are assumed to be absent). Hence, with respect to $\mathrm{La}_{2} \mathrm{CuO}_{4}$, more itinerancy is expected for $\mathrm{YBa}_{2} \mathrm{Cu}_{3} \mathrm{O}_{6}$ along the $c$ axis with consequent gain of $\mathrm{ki}-$ netic energy. A risultant smaller number of holes in the
$3 d_{3 z^{2}-r^{2}}$ orbital of $\mathrm{Cu}(2)$ in $\mathrm{YBa}_{2} \mathrm{Cu}_{3} \mathrm{O}_{6}$ will reduce the value for $q_{\text {val }}$ (because it has negative contribution).

Since the $q_{\text {val }}$ due to one hole in the $3 d_{3 z^{2}-r^{2}}$ is opposite to $q_{\text {val }}$ produced by one hole in the $3 d_{x^{2}-y^{2}}$, we can use the value $q_{\text {val }}\left(3 d_{x^{2}-y^{2}}\right)=95.5 \mathrm{MHz}$ $\left[=-q_{z z}^{\mathrm{val}}\left(3 d_{3 z^{2}-r^{2}}\right)\right]$ for $\mathrm{Cu}^{2+}$, as calculated by Adrian ${ }^{11}$ using Hartree-Fock orbitals, to estimate the number of holes in the $3 d_{3 z^{2}-r^{2}}$ of $\mathrm{Cu}(2)$ needed to reduce $v_{Q_{2}}$ from the calculated value $29.6 \mathrm{MHz}$ to $22.87 \mathrm{MHz}$. We obtain $n_{h}\left(3 d_{3 z^{2}-r^{2}}\right)=0.07$ holes more than in $\mathrm{La}_{2} \mathrm{CuO}_{4}$. Actually, a decrease of the number of holes in the $3 d_{x^{2}-y^{2}}$ can also be responsible for a reduction of $v_{Q 1}$ [see Eq. (2)]. Hence, the relevant quantity which changes with respect to $\mathrm{La}_{2} \mathrm{CuO}_{4}$ is

$$
\Delta=n_{h}\left(3 d_{x^{2}-y^{2}}\right)-n_{h}\left(3 d_{3 z^{2}-r^{2}}\right),
$$

and thus,

$$
\Delta\left(\mathrm{YBa}_{2} \mathrm{Cu}_{3} \mathrm{O}_{6}\right)=\Delta\left(\mathrm{La}_{2} \mathrm{CuO}_{4}\right)-0.07
$$

should hold for $\mathrm{Cu}(2)$ in $\mathrm{YBa}_{2} \mathrm{Cu}_{3} \mathrm{O}_{6}$ in order to obtain agreement with experiment. This indicates that $v_{Q}$ depends sensitively on the $d$-hole distribution. Note that this is also supported by NQR measurements on $\mathrm{Cu}$ in the superconducting ${ }^{28}\left(\mathrm{La}_{0.925} \mathrm{Sr}_{0.075}\right)_{2} \mathrm{CuO}_{4}$ yielding $v_{Q}=35.3 \mathrm{MHz}$. This compound has 0.15 extra holes in the $\mathrm{CuO}_{2}$ plane as compared with $\mathrm{La}_{2} \mathrm{CuO}_{4}$. Some of these holes are at the $\mathrm{Cu}$ atom, and mainly in the $3 d_{x^{2}-y^{2}}$ orbital. Consequently, $q_{\text {val }}$ increases and thus $v_{Q}$ explaining the experimentally observed increase in $v_{Q}$ with respect to the undoped compound.

We now analyze the NQR results for $\mathrm{Cu}(2)$ in the $\mathrm{YBa}_{2} \mathrm{Cu}_{3} \mathrm{O}_{7}$ compound, taking into account that the distance between $\mathrm{Cu}(2)$ and $\mathrm{O}(4)$ is $r^{(1)}=2.28 \AA$, smaller than in $\mathrm{YBa}_{2} \mathrm{Cu}_{3} \mathrm{O}_{6}$, where $r^{(0)}=2.46 \AA^{25}$ Thus, $\mathrm{Cu}(2)$ in $\mathrm{YBa}_{2} \mathrm{Cu}_{3} \mathrm{O}_{7}$ will have stronger covalent bonding with $\mathrm{O}(4)$ than $\mathrm{Cu}(2)$ in $\mathrm{YBa}_{2} \mathrm{Cu}_{3} \mathrm{O}_{6}$ and consequently the increase in the number of holes in the $3 d_{3 z^{2}-r^{2}}$ orbital with respect to $\mathrm{La}_{2} \mathrm{CuO}_{4}$ will be larger than for $\mathrm{YBa}_{2} \mathrm{Cu}_{3} \mathrm{O}_{6}$, since the hopping matrix element $V_{p d \sigma}$ between this orbital and the $p_{z}$ orbital of $\mathrm{O}(4)$ is larger. We can roughly estimate for both compounds the number of holes in the $3 d_{3 z^{2}-r^{2}}$ of $\mathrm{Cu}(2)$ due to the covalent bonding with the $p_{z}$ orbital of $\mathrm{O}(4)$ as given by $n_{h} \sim\left[V_{p d \sigma} /\left(\epsilon_{d}-\epsilon_{p}\right)\right]^{2}$, where $\epsilon_{d}, \epsilon_{p}$ are the on-site energies of both orbitals. Thus, the rate

$$
\rho \equiv n_{h}^{(0)}\left(3 d_{3 z^{2}-r^{2}}\right) / n_{h}^{(1)}\left(3 d_{3 z^{2}-r^{2}}\right)
$$

where index 0 and 1 refer to $\mathrm{YBa}_{2} \mathrm{Cu}_{3} \mathrm{O}_{6}$ and $\mathrm{YBa}_{2} \mathrm{Cu}_{3} \mathrm{O}_{7}$, respectively, is given by

$$
\rho \simeq\left(V_{p d \sigma}^{\mathrm{YBa}_{2} \mathrm{Cu}_{3} \mathrm{O}_{7}} / V_{p d \sigma}^{\mathrm{YBa}_{2} \mathrm{Cu}_{3} \mathrm{O}_{6}}\right)^{2} .
$$

Using the distance dependence of the hopping element $V_{p d \sigma} \sim r^{-7 / 2}$, derived by Harrison, ${ }^{29}$ and inserting the maximum value for $n_{h}^{(0)}\left(3 d_{3 z^{2}-r^{2}}\right)=0.07$ holes estimated before, we obtain approximately 


$$
\begin{aligned}
n_{h}^{(1)}\left(3 d_{3 z^{2}-r^{2}}\right) & =n_{h}^{(0)}\left(3 d_{3 z^{2}-r^{2}}\right)\left(r^{(1)} / r^{(0)}\right)^{-7} \\
& =0.12
\end{aligned}
$$

with respect to the $n_{h}\left(3 d_{3 z^{2}-r^{2}}\right)$ in $\mathrm{La}_{2} \mathrm{CuO}_{4}$. There will also be a difference between the number of holes in the orbital $3 d_{x^{2}-y^{2}}$ of $\mathrm{Cu}$ in the planes for $\mathrm{La}_{2} \mathrm{CuO}_{4}$ and $\mathrm{YBa}_{2} \mathrm{Cu}_{3} \mathrm{O}_{7}$. This difference cannot be estimated in the same way as for the $3 d_{3 z^{2}-r^{2}}$ orbital, since the orbital $3 d_{x^{2}-y^{2}}$ of $\mathrm{Cu}(2)$ has only vanishing hopping elements with $O(4)$. Thus, we obtain a maximum value for

$$
\Delta\left(\mathrm{YBa}_{2} \mathrm{Cu}_{3} \mathrm{O}_{7}\right)=n_{h}^{(1)}\left(3 d_{x^{2}-y^{2}}\right)-n_{h}^{(1)}\left(3 d_{3 z^{2}-r^{2}}\right),
$$

namely,

$$
\Delta\left(\mathrm{YBa}_{2} \mathrm{Cu}_{3} \mathrm{O}_{7}\right)=\Delta\left(\mathrm{La}_{2} \mathrm{CuO}_{4}\right)-0.12 \text {. }
$$

This would imply a reduction of $q_{\mathrm{val}}=-52.1$ by 11 $\mathrm{MHz}$, at most, upon going from $\mathrm{La}_{2} \mathrm{CuO}_{4}$ to $\mathrm{YBa}_{2} \mathrm{Cu}_{3} \mathrm{O}_{7}$. However, the latter high- $T_{c}$ superconductor has more holes, namely $n_{h} \sim 0.25$ holes in the $\mathrm{CuO}_{2}$ planes, ${ }^{16}$ which so far are not included in our analysis. If we make the assumption that these holes are distributed among the $\mathrm{Cu}(2)$ and the two oxygen atoms in the same proportion as in $\left(\mathrm{La}_{0.925} \mathrm{Sr}_{0.075}\right)_{2} \mathrm{CuO}_{4}$, in which the 0.15 holes in the plane produce a frequency increase of $3.4 \mathrm{MHz}$, this will lead (using a linear interpolation) to an increase of $q_{\text {val }}$ by $6 \mathrm{MHz}$. Hence, $q_{\text {val }}$ for $\mathrm{Cu}(2)$ in $\mathrm{YBa}_{2} \mathrm{Cu}_{3} \mathrm{O}_{7}$ will be smaller than for $\mathrm{Cu}$ in $\mathrm{La}_{2} \mathrm{CuO}_{4}$ by $\sim 5 \mathrm{Mhz}$. Thus, if we use our calculated value for

$$
\frac{1}{2} e^{2} Q\left(1-\gamma_{\infty}\right) q_{z z}^{\text {ionic }}=-18.9 \mathrm{MHz}
$$

for $\mathrm{YBa}_{2} \mathrm{Cu}_{3} \mathrm{O}_{7}$ and

$$
q_{\mathrm{val}}=(52.1-5) \mathrm{MHz}=47.1 \mathrm{MHz}
$$

we obtain $v_{Q 2} \simeq 28 \mathrm{MHz}$. The discrepancy with the experimental value of $v_{Q 2}=31.5 \mathrm{MHz}$ is reasonable.

To determine $v_{Q 1}$ in $\mathrm{YBa}_{2} \mathrm{Cu}_{3} \mathrm{O}_{7}$, we note that $\mathrm{Cu}(1)$ has covalent bonds with its four neighboring oxygen atoms within the $y z$ plane. The atomic environment is approximately similar to that of $\mathrm{Cu}$ in $\mathrm{La}_{2} \mathrm{CuO}_{4}$ (since the other two of the six oxygen neighbors are farther away).
Using then $q_{\text {val }}=52.1 \mathrm{MHz}$ as derived for $\mathrm{La}_{2} \mathrm{CuO}_{4}$, and our calculated values for

$$
\frac{1}{2} e^{2} Q\left(1-\gamma_{\infty}\right) q_{z z}^{\text {ionic }}=-32.36 \mathrm{MHz}
$$

and for $\eta,{ }^{30}$ we obtain $v_{Q 1}=21.2 \mathrm{MHz}$. This is in good agreement with experiment. However, on physical grounds one expects $q_{\text {val }}$ in $\mathrm{YBa}_{2} \mathrm{Cu}_{3} \mathrm{O}_{7}$ to be larger than in $\mathrm{La}_{2} \mathrm{CuO}_{4}$ since, in $\mathrm{YBa}_{2} \mathrm{Cu}_{3} \mathrm{O}_{7}, \mathrm{Cu}(1)$ is in the $\mathrm{Cu}^{2.4+}$ state. ${ }^{31}$ Distributing the holes equally among the $3 d y^{2}-z^{2}$ and the $3 d_{3 x^{2}-r^{2}}$ orbitals might change $q_{\text {val }}$ only slightly (the two orbitals contribute with opposite signs). The discrepancy between our calculated value of $\eta_{1}$ and the experimental $\eta_{1}$ for $\mathrm{YBa}_{2} \mathrm{Cu}_{3} \mathrm{O}_{7}$ is probably due to the different electronic density at $\mathrm{O}(1)$ and $\mathrm{O}(4)$. This has a strong effect on the asymmetry parameter, but not on the quadrupole frequency. ${ }^{17}$ This means that $\eta$ must be calculated more accurately including the effect of the $p$ orbitals of the neighboring oxygen atoms.

Our results for $v_{Q}$ and the asymmetry parameter $\eta$ obtained by calculating $\frac{1}{2} e^{2} Q q_{z z}^{\text {ionic }}$ and using Eq. (2) are summarized in Table I. Note that we calculated $\frac{1}{2} e^{2} Q q_{z z}^{\text {ionic }}$ for a crystal consisting of point charges and estimated $q_{\text {val }}$ from experimental results for $\mathrm{Cu}_{2} \mathrm{O}$ and $\mathrm{La}_{2} \mathrm{CuO}_{4}$. As discussed the results for $v_{{ }^{1}}, v_{Q^{2}}$ depend sensitively on the hole distribution. $v_{Q}$ could even be a good measure of the number of holes in the $\mathrm{CuO}_{2}$ planes. But for a precise analysis $\gamma_{\infty}$ remains a problem. Note that taking different values of $\gamma_{\infty}$ can change the results dramatically. ${ }^{14}$ Therefore, the use of higher-order terms than those of Eq. (2) in the expression of the quadrupole frequency makes no sense.

It is of interest to note that charge fluctuations on $\mathrm{Cu}$ and $O$ sites need not be considered explicity to explain experimental results. $\mathrm{NQR}$ experiments on $\mathrm{YBa}_{2} \mathrm{Cu}_{3} \mathrm{O}_{7-8}$ as a function of $\delta$ and $\mathrm{Ga}$ and $\mathrm{Zn}$ doping [which has interesting influence on $T_{c}$ (Ref. 32)] could give further useful information.

We are grateful to V. Müller and H. Riesemeier for many useful discussions. This work was supported by the Bundesministerium für Forschung und Technologie.
${ }^{1} \mathrm{H}$. Lütgemeier and M. W Pieper, Solid State Commun. 64, 267 (1987).

${ }^{2}$ R. E. Walstedt, W. W. Warren, Jr., R. F. Bell, G. F. Brennert, J. P. Remeika, R. J. Cava, and E. A. Reitman, Phys. Rev. B 36, 5727 (1987); W. W. Warren, Jr., R. E. Walstedt, G. F. Brennert, G. P. Espinosa, and J. P. Remeika, Phys. Rev. Lett. 59, 1960 (1987).

${ }^{3}$ H. Riesemeier, Ch. Grabow, E. W. Scheidt, V. Müller, K. Lüders, and D. Riegel, Solid State Commun. 64, 309 (1987).

${ }^{4}$ M. Mali, D. Brinkman, L. Pauli, J. Roos, H. Zimmermann, and J. Hulliger, Phys. Lett. A 124, 112 (1987).

${ }^{5}$ C. H. Pennington, D. J. Durand, D. B. Zax, C. P. Slichter, J. P. Rice, and D. M. Ginsburg, Phys. Rev. B 37, 7944 (1988).

${ }^{6}$ H. Riesemeier, J. Pattloch, K. Lüders, and V. Müller, Solid State Commun. 68, 251 (1988)

${ }^{7}$ Hiroshi Yasuoka, Tadashi Shimizu, Yutaka Ueda, and Koji
Kosuge, J. Phys. Soc. Jpn. 57, 2659 (1988).

${ }^{8}$ Chester T. O'Konski and Tae-Kyu Ha, J. Chem. Phys. 49, 5354 (1968); C. T. O'Konski in Determination of Organic Structures by Physical Methods, edited by F. C. Nachod and J. J. Zuckerman (Academic, New York, 1962), Vol. 2, Chap. 11.

${ }^{9}$ J. L. De Vries, C. P. Keijzers, and E. de Boer, Inorg. Chem. 11, 1343 (1972).

${ }^{10}$ R. M. Sternheimer, Phys. Rev. 80, 102 (1950); R. M. Sternheither, Phys. Rev. 84, 244 (1951).

${ }^{11}$ Frank J. Adrian, Phys. Rev, B 38, 2426 (1988).

${ }^{12}$ R. E. Watson and A. J. Freeman, Phys. Rev. 131, 250 (1963).

${ }^{13}$ R. P. Gupta and S. K. Sen, Phys. Rev. A 8, 1169 (1973).

${ }^{14}$ Using $\gamma_{\infty}^{\mathrm{Cu}^{2+}}=-7.59$ the calculation by Adrian (see Ref. 11) would give $v_{Q 1}=56.24 \mathrm{MHz}$ and $v_{Q 2}=51.4 \mathrm{MHz}$ for $\mathrm{YBa}_{2} \mathrm{Cu}_{3} \mathrm{O}_{7}$.

${ }^{15}$ M. Tosi, Solid State Phys. 16, 1 (1964). 
${ }^{16}$ Y. Tokura, J. B. Torrance, T. C. Huang, and A. I. Nazzal, Phys. Rev. B 38, 7156 (1988).

${ }^{17} \mathrm{We}$ have calculated $\frac{1}{2} e^{2} Q q_{z z}^{\text {ionic }}$ for different charge configurations resulting from a redistribution of the holes within the planes and chains and between them. $\frac{1}{2} e^{2} Q q_{z z}^{\text {ionic }}$ is almost independert if these changes are small, whereas $\eta_{\text {ionic }}=\left(q_{x x}^{\text {ionic }}-q_{y y}^{\text {ionic }}\right) / q_{z z}^{\text {ionic }}$ is very sensitive to changes in the charge distribution among the oxygen atoms surrounding $\mathrm{Cu}(1)$ and $\mathrm{Cu}(2)$

${ }^{18}$ Experimental resulis for the quadrupole frequency as a function of the volume show clearly the ionic character of $\mathrm{Cu}_{2} \mathrm{O}$ (see Ref. 19).

${ }^{19}$ T. Kushida, G. B. Benedek, and N. Bloembergen, Phys. Rev. 104, 1364 (1956).

${ }^{20}$ Using $\gamma_{\infty}=-17$ (see Ref. 12), we derive from Eq. (2) $q_{\mathrm{val}}=-46.2 \mathrm{MHz}$ which is not acceptable for an ionic compound, since $q_{\mathrm{val}} \neq: 0$ iraplies that $\mathrm{Cu}$ is not completely in a $3 d^{10}$ state, but in iz hybridized state $\psi=\alpha\left|3 d^{10}\right\rangle+\beta\left|3 d^{9} 4 s\right\rangle$. To obtain the preceding value for $q_{\text {val }}$ we need $\sim 0.4$ holes in the $d$ shell, too large for an ionic compound. In conclusion, the correct value for $\gamma_{\infty}$ must be much smaller than $(-17)$ to obtain $q_{\text {val }} \simeq 0$. It is well known (see Ref. 21) that the calculated antishielding factors are not always in good agreement with the experimentally measured enhancement of the electric field gradients. For the case of $\mathrm{Cu}_{2} \mathrm{O}$, Bersohn (see Ref. 22) already pointed out that the agreement is only within a factor of two (if one fits $\gamma_{\infty}$ from the experimental $v_{Q}$ using the ionic model). Consequently, we conclude that $q_{\mathrm{val}} \simeq 0$ for $\mathrm{Cu}_{2} \mathrm{O}$ is a more reasonable assurnption (and $\gamma_{\infty} \neq-17$ ).

${ }^{21}$ R. E. Watson and A. J. Freeman, in Hyperfine Interactions, edited by A. J. Freeman and R. B. Frankel (Academic, New York, 1967), Chap. 2.

${ }^{22}$ Richard Bersohn, J. Chem. Phys. 29, 326 (1958).

${ }^{23}$ H. Krüger and U. Meyer-Berkhout, Z. Phys. 132, 171 (1952).

${ }^{24}$ S. Nagel, J. Phys. Chem. Solids 46, 743 (1985).

${ }^{25}$ Frank Herman, Robert V. Kasowski, and William Y. Hsu, Phys. Rev. B 36, 6904 (1988).

${ }^{26}$ Toshinobu Tsuda, Tadashi Shimizu, Hiroshi Yasuoka, Kohoji Kishio, and Koichi Kitazawa, J. Phys. Soc. Jpn. 57, 2908 (1988).

${ }^{27}$ R. M. Sternheimer, Phys. Rev. 164, 10 (1967).

${ }^{28} \mathrm{Kenji}$ Ishida, Yoshio Kitaoka, and Kunisuke Asayama, J. Phys. Soc. Jpn. 58, 36 (1989).

${ }^{29}$ W. A. Harrison, Electronic Structure and the Properties of Solids (Freeman, San Francisco, 1980).

${ }^{30}$ We have assumed $q_{x x}^{\mathrm{val}}=q_{y y}^{\mathrm{val}}=q_{z z}^{\mathrm{val}} / 2$, since the nonionic contribution to the field gradients is due to $d$ electrons with equal charge density along the $x$ and $y$ principal axes.

${ }^{31} \mathrm{We}$ have used as antishielding factor for $\mathrm{Cu}(1)$ in $\mathrm{YBa}_{2} \mathrm{Cu}_{3} \mathrm{O}_{7}$ $\left(\mathrm{Cu}^{2,4+}\right)$ the quantity $\gamma_{\infty}=x \gamma_{\infty}^{\mathrm{Cu}^{2+}}+(1-x) \gamma_{\infty}^{\mathrm{Cu}^{3+}}$, where $x=0.6$ is the concentration of $\mathrm{Cu}^{2+}$ in $\mathrm{Cu}^{2,4+}$, $\gamma_{\infty}^{\mathrm{Cu}^{2+}}=-7.59$, and $\gamma_{\infty}^{\mathrm{Cu}^{3+}}=-7.04$ (see Ref. 11).

${ }^{32}$ Gang Xiao, M. Z. Cieplak, A. Gavrin, F. H. Streitz, A. Bakhshai, and C. L. Chien, Phys. Rev. Lett. 60, 1446 (1988). 